\title{
A planar UWB semicircular-shaped monopole antenna with quadruple band notch for WiMAX, ARN, WLAN, and X-Band
}

\author{
Majed O. Al-Dwairi \\ Faculty of Engineering Technology/Communication Technology Engineering Department, \\ Al-Balqa Applied University, Jordan
}

\begin{tabular}{l} 
Article Info \\
\hline Article history: \\
Received Jun 15, 2019 \\
Revised Sep 29, 2019 \\
Accepted Oct 6, 2019 \\
\hline Keywords: \\
ARN \\
Quadruple band notch \\
UWB antenna \\
WiMAX \\
WLAN \\
X-Band \\
\hline
\end{tabular}

\begin{abstract}
This paper proposed quadruple notched frequency bands ultra-wideband (UWB) antenna. The antenna is a semicircular-shaped monopole type of a compact size $36 \times 24 \mathrm{~mm}$, covering frequency range of $3.02-14 \mathrm{GHz}$. Four rejected narrow bands including WiMAX (3.3-3.7GHz), ARN (4.2-4.5 $\mathrm{GHz})$, WLAN (5.15-5.825GHz), X-Band (7.25-7.75) have been achieved using inserting slots techniques in the patch, feed line, and ground plane. The slots dimensions have been optimized for the required reject bands. The antenna design and analysis have been investigated by simulation study using CST-EM software package. The antenna characteristics including impedance bandwidth, surface current, gain, radiation efficiency, radiation pattern have been discussed.
\end{abstract}

Copyright $@ 2020$ Institute of Advanced Engineering and Science. All rights reserved.

\section{Corresponding Author:}

Majed Dwairi,

Faculty of Engineering Technology/Communication Technology Engineering department,

Al-Balqa Applied University,

As-Salt, Jordan.

Email: majeddw@bau.edu.jo

\section{INTRODUCTION}

After authorization the unlicensed Ultra-wide band UWB (3.1-10.6) GHz by the federal communication commission (FCC) in 2002 [1], many researchers concentrated on the use of this range due to many interesting features such as low profile, small size, easy to fabricate, its omnidirectional pattern, and the most significant feature its fabrication with the printed circuit boards. The investigation of the monopole patch antenna in UWB takes different areas such as studying the effect of inserting different fractal slots on the patch [2-4] or enhancing the impedance bandwidth [5].

One of the most important challenges in designing UWB antennas is the presence of narrow bands within the UWB, such as: WiMAX (Worldwide Interoperability for Microwave Access, operating bandwidth 93.3-3.7GHz), ARN (Aeronautical Radio Navigation, operating bandwidth 4.2-4.5 GHz), WLAN (Wireless Local Area Network, operating bandwidth 5.15-5.825GHz), X-Band ( a segment of the superhigh-frequency radio spectrum that lies between $5.2 \mathrm{GHz}$ and $10.9 \mathrm{GHz}$ and is used especially for radars and for spacecraft communication, our investigating babdwidth 7.25-7.75), so it will be interfering with the operating UWB. To reject these unwanted narrow bands different method was investigated by inserting filters within the UWB antenna with a rejection characteristic, to eliminate the effect of electromagnetic interference (EMI). Many works concentrated the rejection of more than one band, many designers have been published works including dual-band reject [6-13], triple band reject [14-17], four band reject [18-26]. The researchers used different antenna types configuration and different slots configurations to achieve the desired notch filter for a desired narrow band rejection, the slot configuration was inserted on the radiating elements of the patch, depending on the notch frequency and the calculated length of the slot for each notch filter. In [6] the authors used circular monopole patch antenna with inserting mirrored L-shaped on the feet of the monopole, and spilt 
ring resonator SRR on the patch to eliminate WiMAX and WLAN respectively, while in [7] used rectangular planer antenna consisting of a radiating patch with a staircase slots with a partial rectangular ground, inserting meandered slot on the patch and U-shaped slot on the feed to reject WiMAX and WLAN respectively. The authors in [8] used squared patch with partial ground and slotted conductor packed plane, by inserting on the slotted conductor packed pair of mirror L-shaped slots, and U-shaped slot receiving a rejection of WLAN and WiMAX bands respectively. Different planer antenna shaped have been investigated by using one or more U-shaped slot on the patch to achieve WiMAX and WLAN band rejection [9-11]. A compact lamp-shaped antenna was designed and inserted a quarter L-shaped slot on the patch and two quarter L-shaped on the ground in order to eliminate the effect of WiMAX and WLAN respectively [12]. In [13] a square patch with partial ground was modified by inserting a composed of modified fork-shaped and $\Omega$-shaped slot and a pair of $\Gamma$-shaped to eliminate the effect of WiMAX and WLAN.

Different methods of design have been presented for an effective narrow band rejection by introducing different etching slots on the patch or ground obtaining desired notched bands in UWB, introducing three notched bands. In $[14,15]$, they introduced three band notched UWB antenna by inserting a Hiulbert slot etched on the half eleptic shaped patch, and a slot rectangular shaped etched on the half eleptic ground [14], or etching out 2 elliptic single complementary split ring resonator on the patch with a proper dimensions and placing 2 rectangular on the pack[15]. An UWB triple band-notched antenna has been proposed in [16] by inserting a rectangular strip and two nested U-shaped slots in the antenna patch and feed, which can filter WiMAX, C-band, WLAN and X-band applications. In [17] received three high rejection notch bands characteristics by insetting two U-shaped and one T-shaped on the patch on the urn shaped monopole antenna.

To realize UWB antenna with four bands notched characteristics, the authors introduced a trapezoidal antenna [18], and an embedded ellipse at top of trapezoidal patch (named ellipsoidal) [19], a U-shaped and a pair of C-shaped band stop filters have been etched on the patch antenna and the partial ground with a proper dimensions achieving a band-rejection characteristic in the WiMAX (3.43-3.85 GHz), WLAN(5.26-6.01 GHz), X-band satellite communication (7.05-7.68 GHz), and ITU $8 \mathrm{GHz}$. While in [19], the authors achieved four band reject characteristics for WiMAX, ARN, WLAN, and ITU-8 bands by etching several U-shaped and single I-shaped only on the patch. In [20] presented four sharp notch filtering for WiMAX, INSAT, lower, and upper WLAN, while exhibiting stable radiation pattern over the hole range of ultra-wide band, this achieved by inserting a complementary split ring resonators (CSRRs) on the centered semi-circular shaped radiator with partial ground plane. Four filter band are presented by creating different shapes cut U, L, and C-shaped on a rectangular microstrip antenna [21].

Many authors achieved four band notched filters by modified the patch antenna of different shapes with a coplanar waveguide (CPW) [22-25]. In [26-28] the authors introduced five bands notched filters by utilizing Y-shaped patch with a combinations of U-shaped etched slots [26], semi-circle patch with U-shaped etched on the partial ground and CSRRs on the patch [27], in [28] the authors used different sizes of rectangular split- ring resonators on the radiating patch and the feed line achieving five bands notched filters. This paper proposed quadrable notched ultra-wideband antenna which is modification of [6] by adding a rectangular slot, etching U-shaped slot on the patch, and inverted L-shaped on the partial ground. Four rejection bands are received the results of the proposed antenna were compared with other works designed previously.

\section{ANTENNA DESIGN AND STRUCTURE}

The proposed quadrupole stops band circular antenna geometry consisting of central circle radiator with tow circle radius $5.36 \mathrm{~mm}$ on both sides apart from the center $5 \mathrm{~mm}$ and partially ground plane, the top, bottom, and side view are shown in Figure 1(a), (b), and (c). the antenna was designed on 36x24 mm FR-4 substrate material of thickness (tp) $1.6 \mathrm{~mm}$, loss tangent 0.02 , and permittivity ( $\square \mathrm{r}$ ) 4.3 . The antenna was fed using $50 \Omega$ microstrip feed line length $17 \mathrm{~mm}$ and width $2 \mathrm{~mm}$. The optimal parameter dimensions for the investigated antenna and the parameters that used to design the notch slots for each notch filter are presented in Table 1. The antenna optimization and simulation were carried using CST-Microwave Studio2018. Figure 2(a)-(d) shows the dimensions for each notch slot that used for rejection of WiMAX, ARN, WLAN, and X-band respectively.

Table 1. Optimized parameter for antenna and quadruple band notch filters

\begin{tabular}{|c|c|c|c|c|c|c|c|c|c|c|c|c|c|c|c|}
\hline Parameter & $\mathrm{L}_{\mathrm{S}}$ & $\mathrm{W}_{\mathrm{S}}$ & $\mathrm{L}_{\mathrm{f}}$ & $\mathrm{W}_{\mathrm{f}}$ & $\mathrm{t}_{\mathrm{s}}$ & $t_{p}$ & $\mathrm{R}_{\mathrm{p} 1}$ & $\mathrm{R}_{\mathrm{p} 2}$ & $\mathrm{R}_{\mathrm{p} 3}$ & $\mathrm{R}_{\mathrm{p} 4}$ & $\mathrm{R}_{\mathrm{p} 3}-\mathrm{R}_{\mathrm{p} 4}$ & $\mathrm{~d}$ & $\mathrm{~L}_{\mathrm{n} 1}$ & $\mathrm{~L}_{\mathrm{n} 2}$ & $\mathrm{~L}_{\mathrm{n} 3}$ \\
\hline Value (mm) & 36 & 24 & 17 & 2 & 1.6 & 0.009 & 8.5 & 5.36 & 3.8 & 3.51 & 0.20 & 5 & 1.2 & 4.65 & 8.6 \\
\hline Parameter & $\mathrm{L}_{\mathrm{n} 4}$ & $\mathrm{~L}_{\mathrm{p} 1}$ & $\mathrm{~L}_{\mathrm{p} 2}$ & $\mathrm{~L}_{\mathrm{p} 3}$ & $\mathrm{w}_{\mathrm{p} 1}$ & $\mathrm{w}_{\mathrm{p} 2}$ & $\mathrm{w}_{\mathrm{p} 3}$ & $\mathrm{~W}_{\mathrm{n} 1}$ & $\mathrm{~W}_{\mathrm{n} 2}$ & $\mathrm{~L}_{\mathrm{g}}$ & $\mathrm{L}_{\mathrm{g} 1}$ & $\mathrm{~L}_{\mathrm{g} 2}$ & $\mathrm{~W}_{\mathrm{g} 1}$ & \multicolumn{2}{|c|}{$\mathrm{W}_{\mathrm{g} 2}$} \\
\hline Value (mm) & 3.65 & 1.5 & 0.22 & 2.9 & 10 & 15 & 0.21 & 1.4 & 1 & $15^{5}$ & 0.5 & 3.5 & 9 & $0.3^{5}$ & \\
\hline
\end{tabular}




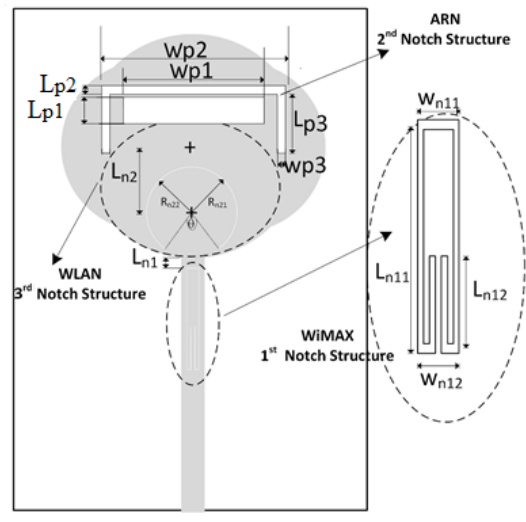

(a)

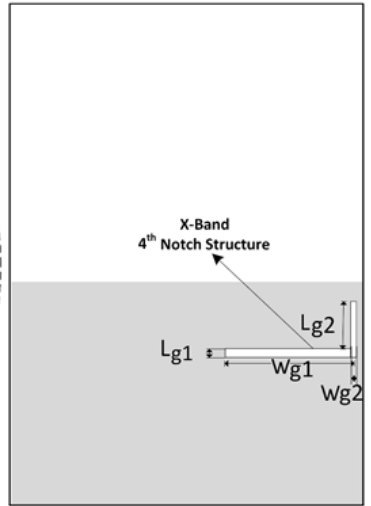

(b)

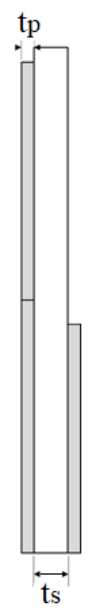

(c)

Figure 1. Proposed quadruple band notched antenna (a) front view, (b) back view, (c) side view

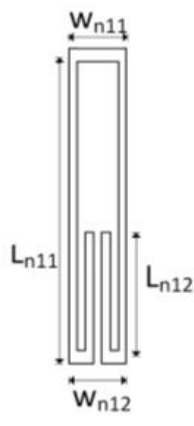

(a)

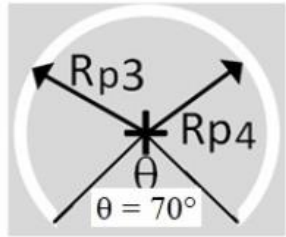

(c)

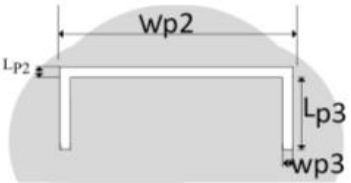

(b)

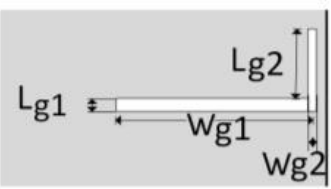

(d)

Figure 2. The optimized dimensions of the selected shaped slots for each notch characteristics (a) Mirrored shaped slot for WiMAX band, (b) inverted U-shaped for ARN (Aeronautical Radio Navigation) band,

(c) A split ring resonator for WLAN band (d) L-shaped inverted counterclockwise $90^{\circ}$ for X-band

\section{METHODOLOGY OF DESIGN}

To design UWB with quadruple notched band antenna, two main things must be considered, firstly design an antenna capable to cover the UWB, secondly removing the interference caused by narrow bands within the operating UWB.

\subsection{Chosen the proper form for monopole UWB antenna}

Figure 3 present the investigated monopole antennas configurations to choose the proper form for UWB, three different antennas design were investigated, case 1 with circular form radius 8.5 mm, case 2 the same form with adding two side circles aside from the center $5 \mathrm{~mm}$ with radius $5.36 \mathrm{~mm}$, and case 3 antenna with inserted rectangular slot on the patch with dimensions $10 \mathrm{X} 2 \mathrm{~mm}$. Figure 4 demonstrated the return loss $\left|S_{11}\right|$ for three cases over the operating frequencies. The comparison between these three cases is listed in Table 2, which evident that case 3 is the best case for the operating UWB that will be used further in the design of final antenna with quadruple notched filters. 


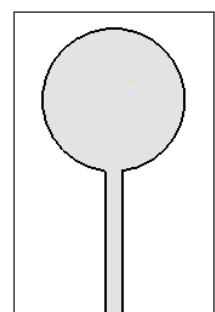

(a) Front view case 1

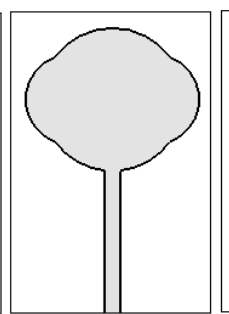

(b) Front view
case 2

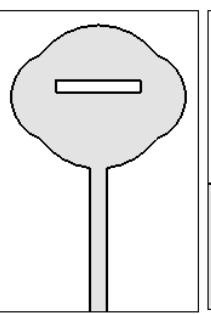

(c) Front view case 3

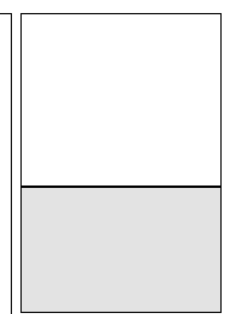

(d) back view ground

Figure 3. Three cases of proposed monopole antennas design for quadruple UWB notch filters

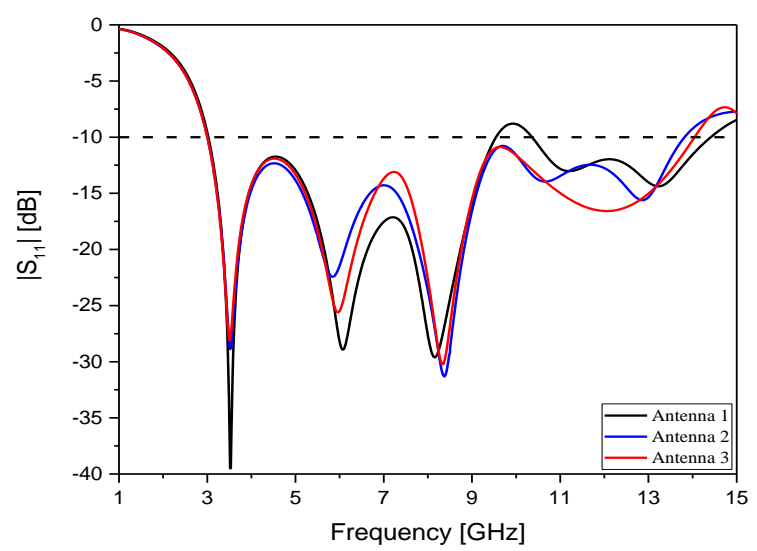

Figure 4. Simulated $|\mathrm{S} 11|$ (return loss) of three cases of the proposed UWB antenna configuration

Table 2. Comparison between different antenna modifications

\begin{tabular}{llll}
\hline Feature & Antenna 1 & Antenna 2 & Antenna 3 \\
\hline Pass band [GHz] & $3.03-9.54$ & $3.01-13.82$ & $3.02-14$ \\
Resonant frequency [GHz] & $3.53,6.06,8.15$ & $3.55,5.86,8.38,10.65,12.9$ & $3.5,6,8.34,12$ \\
Slot & - & - & Rectangular shape \\
\hline
\end{tabular}

\subsection{Surface current distribution}

First of all, the surface current distribution was investigated for case 3 to observe the concentration of the surface current distribution of the monopole antenna in order to choose the proper places to insert slots for notched different bands, from Figure 5(a)-(c) the current distribution is mainly concentrated in the edge rather than in the center of the monopole for different resonate frequencies.
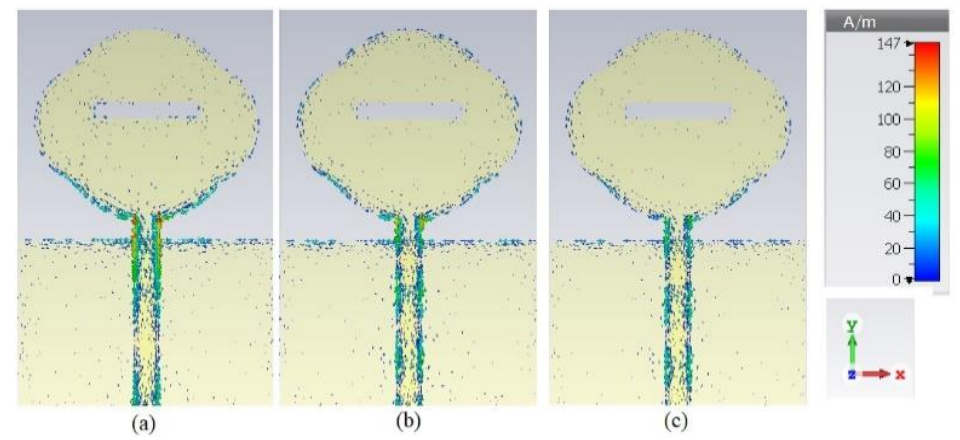

Figure 5. Current distribution for different resonant frequencies within the chosen antenna case 3 (a) $3.5 \mathrm{GHz}$, (b) $6 \mathrm{GHz}$, and (c) $8.34 \mathrm{GHz}$ 


\section{NOTCH BANDS}

This section will introduce the four notched bands of the investigated monopole antenna to eliminate the effect of the unwanted electromagnetic interferences of UWB communication systems with WiMAX, ARN, WLAN, and X-Band frequencies band. Taking in to account the relationship between the notch frequency and the total length of the etched slot has been estimated by (1) expressed in [11].

$$
f_{\text {notch }}=\frac{c}{2 L \sqrt{\varepsilon_{\text {eff }}}}
$$

Where, $\mathrm{c}$ is the speed of the light in free space and $\varepsilon_{\text {eff }}$ is the effective dielectric constant $\varepsilon_{\text {eff }}=\left(1+\varepsilon_{r}\right) / 2$ The four steps to achieve the quadrupole band notched monopole UWB were done as follow:

\subsection{WiMAX notch filter design}

To eliminate the electromagnetic interference for the first lower notch frequency $3.5 \mathrm{GHz}$ for the narrow band WiMAX-IEEE 802.16 that operate at $3.3-3.7 \mathrm{GHz}$, is achieved by inserting a proper mirrored L-shaped connected from the top slot is etched on the feed line as shown in Figure 2 (a). Using (1) for this band to be approximately equal to the halfwave length at the center frequency, the calculated length of the notch slot is listed in Table 3. The total length of the inserted slot is given in (2).

$$
L_{\text {Total }}=2 L_{n 3}+2 L_{n 4}+W_{n 1}+W_{n 2}
$$

Parametric study was done to optimize the bandwidth of the rejected WiMAX band, it would be effective to control the slot length, given in (2), by varying some parameters $\mathrm{L}_{\mathrm{n} 3}$ and $\mathrm{L}_{\mathrm{n} 4}$. The optimized length the parameters is listed in Table 3, Figure 6 demonstrate the control of the first notch slot length by varying $\mathrm{L}_{\mathrm{n} 4}$ with constant $\mathrm{L}_{\mathrm{n} 3}$, and vice versa.

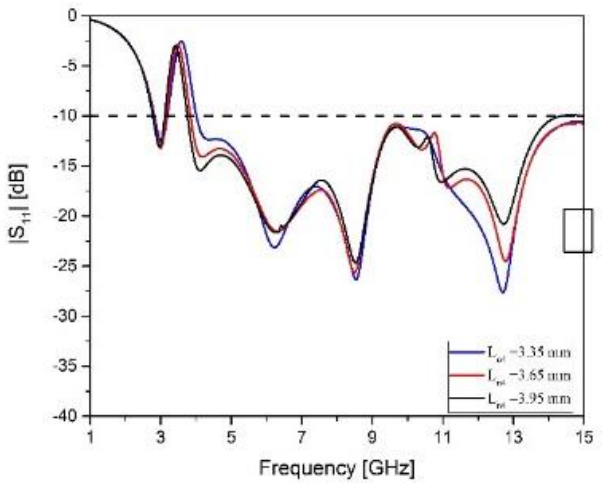

(a)

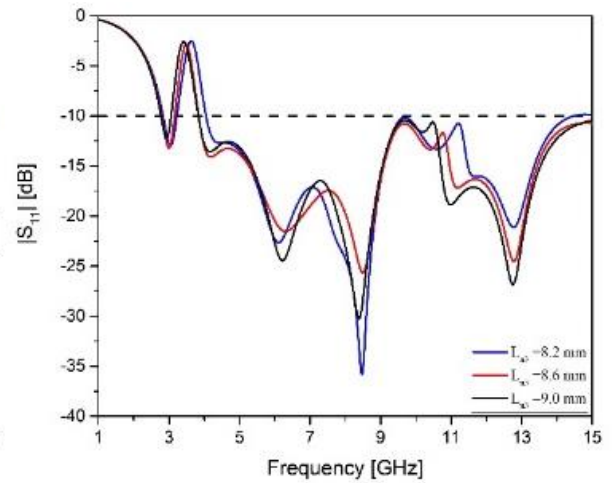

(b)

Figure 6. Optimization WiMAX notch filter: the effect of varying Ln3, and Ln4 on the notch frequency $3.5 \mathrm{GHz}$, (a) varying Ln3 with constant Ln4, (b) varying Ln4 with constant Ln3

\subsection{ARN notch filter design}

To eliminate the effect ARN band 4.25-4.85 GHz, inverted U-shaped was etched on the patch with optimized dimensions shown in Figure 2(b) and listed in Table 1. The calculated length of the inserted slot to be approximately equal to the halfwave length at the center frequency was done using (1), is listed in Table 3, while total length of the notch slot is given in (3).

$$
L_{\text {Total }}=W_{P 2}+2 L_{P 3}
$$

In order to receive the proper length of the etched slot a parametric study was done to determine the optimized length of (3) by varying Wp2 with constant Lp3 and vice versa to receive notch frequency of the second notch filter approximately equal to the calculated length using (1), the optimized length is listed in Table 3, which received $20.8 \mathrm{~mm}$, less than the calculated in $0.38 \mathrm{~mm}$. Figure 7 demonstrate the effect of the varying Wp2 and Lp3 on the second notch frequency $4.35 \mathrm{GHz}$. 

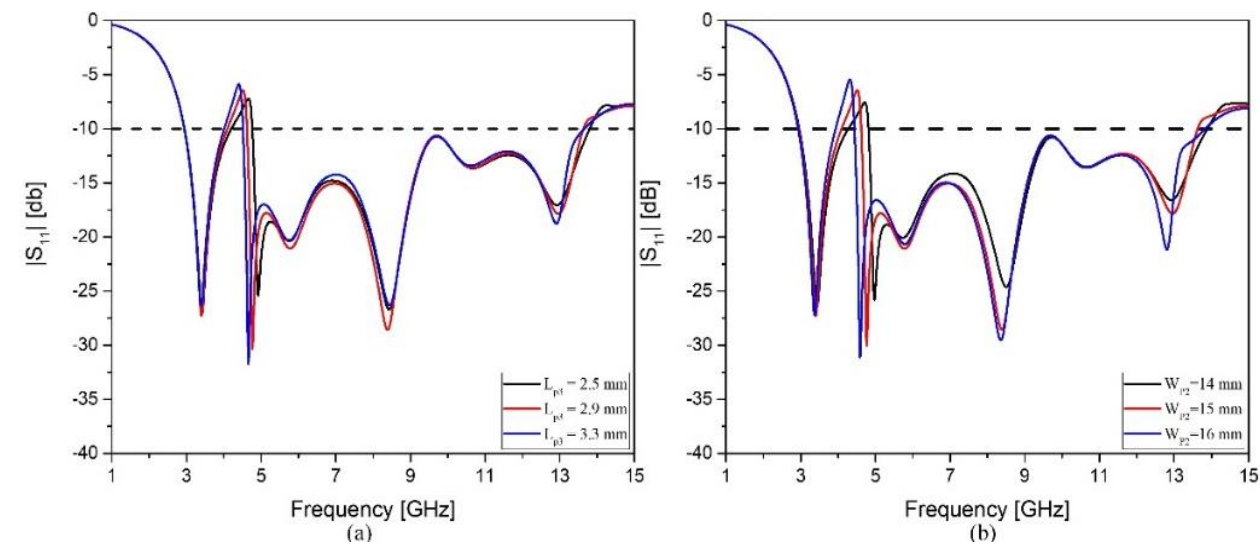

Figure 7. Optimization ARN notch filter: the effect of varying $\mathrm{L}_{\mathrm{P} 3}$, and $\mathrm{W}_{\mathrm{P} 2}$ on the notch frequency $4.35 \mathrm{GHz}$, (a) varying $\mathrm{L}_{\mathrm{P} 3}$ with constant $\mathrm{W}_{\mathrm{P} 2}$, (b) varying $\mathrm{W}_{\mathrm{P} 2}$ with constant $\mathrm{L}_{\mathrm{P} 3}$

\subsection{WLAN notch filter design}

To eliminate the effect of WLAN that operate at 5.15-5.825 GHz, a split ring resonator SRR with an optimized parameter as listed in Table 1 , was inserted at distance $L n 2=4.65 \mathrm{~mm}$ from the center of the main monopole as demonstrated in Figure 2 (c). Using (1) using the notch frequency of WLAN band which equal to $5.5 \mathrm{GHz}$, the calculated length received equal $16.75 \mathrm{~mm}$ that expected to be the length of the inserted SRR perimeter, determined using (4)

$$
L_{\text {Total }}=2 \pi R_{P 3}-\left(R_{P 3} \times \frac{\theta}{180} \pi\right)
$$

Where $\theta$-is the open part of the SRR.

To determine the effect of varying parameter $\mathrm{R}_{\mathrm{P} 3}$ in (4), on the peremeter length of the etched SRR slot to receive the total length equal to the halfwave length at the center frequency $5.5 \mathrm{GHz}$, receiving in (1), a parametric study was done. The proper length of the outer radius of the SRR with constant arc cut with angle $\theta=70 \mathrm{o}$, and constant difference between the outer and the inner radius of SRR equal $0.20 \mathrm{~mm}$, receiving the optimized outer radius $\mathrm{R}_{\mathrm{P} 3}=3.8 \mathrm{~mm}$ and the inner radius $\mathrm{R}_{\mathrm{P} 4}=3.60 \mathrm{~mm}$.

Figure 8 (a), shows the simulated |S11| for different outer radius of SRR $R_{\mathrm{P} 3}$, with constant difference $R_{P 3}-R_{P 4}=0.20 \mathrm{~mm}$. from Figure 8 (a), it is seen that the significant effect on $t$ the notch frequency by varying the outer radius, were the best one for $\mathrm{R}_{\mathrm{P} 3}=3.8 \mathrm{~mm}$. In order to choose the proper difference between the outer and the inner radius of SRR, a parametric study was done for different distance with constant outer radius $\mathrm{R}_{\mathrm{P} 3}=3.8 \mathrm{~mm}$. Figure 8 (b) shows the simulated $|\mathrm{S} 11|$ with changing the difference between $\mathrm{R}_{\mathrm{P} 3}$ and $\mathrm{R}_{\mathrm{P} 4}$.
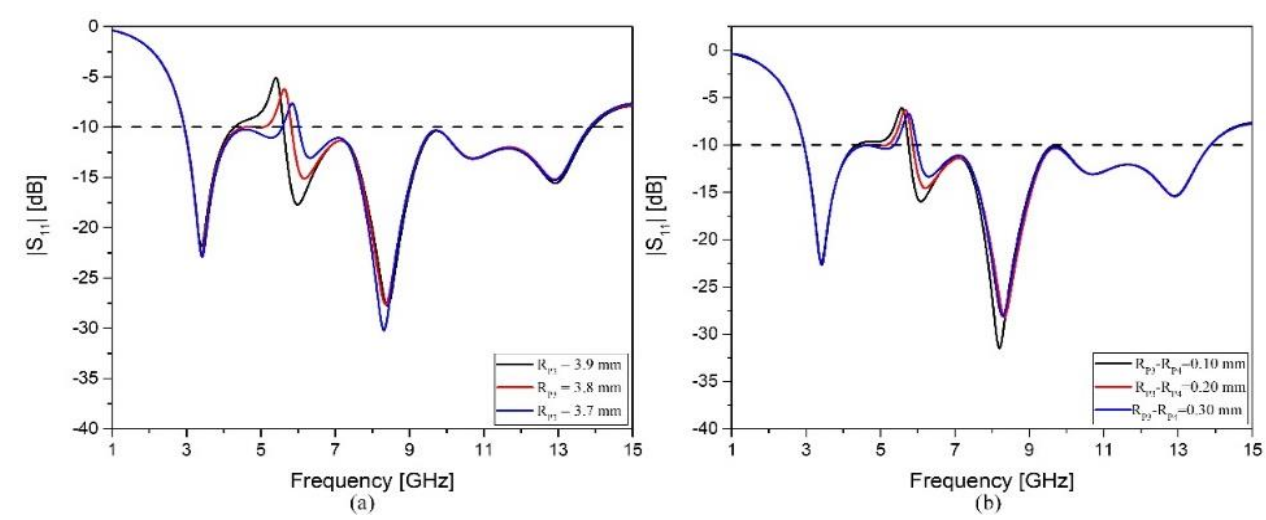

Figure 8. The simulated $\left|S_{11}\right|$ for optimization WLAN notch filter: the effect of varying $R_{\mathrm{P} 3}$ and $\mathrm{R}_{\mathrm{P} 3}-\mathrm{R}_{\mathrm{P} 4}$,

(a) varying $R_{\mathrm{P} 3}$ with constant $\mathrm{R}_{\mathrm{P} 3}-\mathrm{R}_{\mathrm{P} 4}=0.29 \mathrm{~mm}$, (b) varying $\mathrm{R}_{\mathrm{P} 3}-\mathrm{R}_{\mathrm{P} 4}$ with constant $\mathrm{R}_{\mathrm{P} 3}=3.8 \mathrm{~mm}$ 


\section{4. $X$-Band notch filter design}

To eliminate the effect of X-band which operate at 7.25-7.85 GHz, an L-shaped slot was etched on the partial ground with optimized parameters recorded in Table 1 and demonstrated in Figure 2(d). According to (1) the calculated length of the inserted slot on the partial ground taking into account the notch frequency 7.5 GHz of the X-Band, the calculated length equal to $12.29 \mathrm{~mm}$. the total length of the simulated slot given in (5). The proper length of $\mathrm{W}_{\mathrm{g} 1}$ and $\mathrm{L}_{\mathrm{g} 2}$ received after parametric study are listed in Table 2, and the total optimized length received $19.23 \mathrm{~mm}$, Figure 9 shows the simulated $|\mathrm{S} 11|$ for optimization X-Band notch filter.

$$
L_{\text {Total }}=W_{g 1}+L_{g 2}
$$

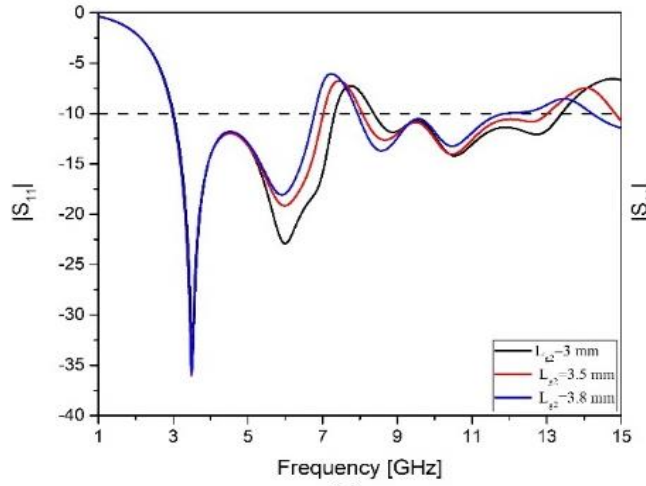

(a)

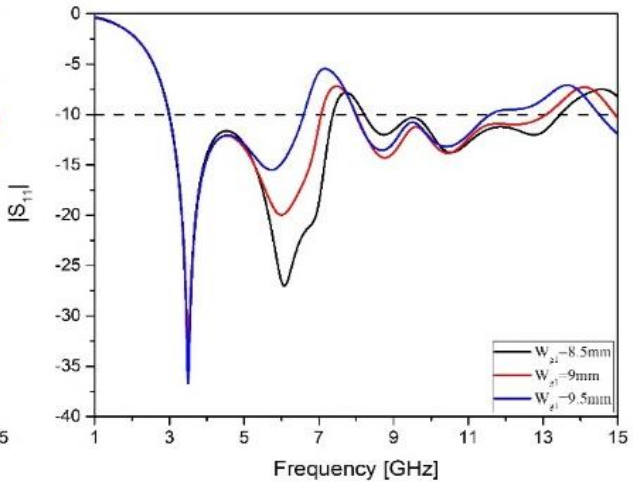

(b)

Figure 9. The simulated $\left|S_{11}\right|$ for optimization X-Band notch filter: (a) the effect of varying $\mathrm{L}_{\mathrm{g} 2}$ with constant $\mathrm{W}_{\mathrm{g} 1}$, (b) the effect of varying $\mathrm{W}_{\mathrm{g} 1}$ with const $\mathrm{L}_{\mathrm{g} 2}$

\section{RESULTS AND DISCUSSION}

The simulated return loss $\left|S_{11}\right|$ of the reference antenna case 3 and the final antenna with quadruple notched band filters demonstrated in Figure 10, while the VSWR shown in Figure 11. The operating UWB is (2.77-13.83) $\mathrm{GHz}$ with $133.5 \%$ fractional bandwidth of the final antenna. Table 3 listed a comparison between these different 4 stages with each narrow band from table evident that the received resonant frequency for each simulated band is approximately the same as the original band. From Figure 11 evident that WiMAX gives the best rejection bandwidth with VSWR 7 at resonant frequency followed ARN, WLAN and X-Band respectively, the worst one is X-Band with VSWR 2.9 at resonant frequency. The reason here due to for collecting all four rejection bands in one antenna, however improving the rejection band will affect the other, while the best compramize chosen and presented here. Figure 12 shown the effect of combination of the four filters together, from the figure, it is evident that a wider bandwidth for ARN filtering case has been achieved while another bandwidth remains same or became little smaller.

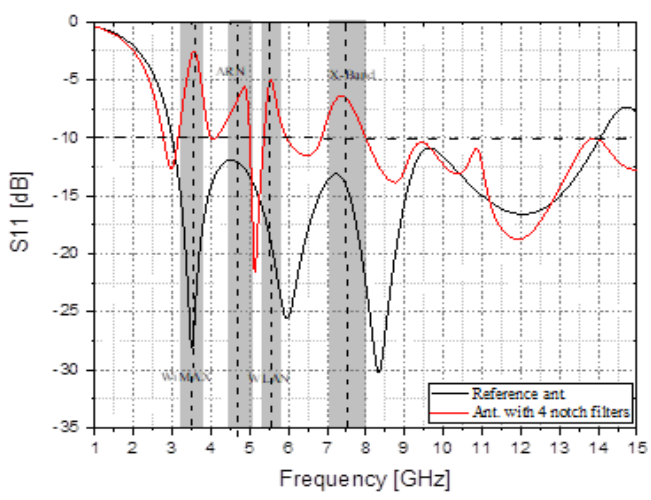

Figure 10. The simulated S11 for the reference monopole antenna case 3 and the monopole antenna with quadruple notched filters 
Table 3. Comparison of different stages for each proposed band notch with each narrow band

\begin{tabular}{lllll}
\hline Band notch $\rightarrow$ Characteristics $\downarrow$ & WiMAX & ARN & WLAN & X-band \\
\hline Bandwidth [GHz] & $3.3-3.7$ & $4.2-4.5$ & $5.15-5.825$ & $7.25-7.75$ \\
Simulated BW [GHz] & $3.18-3.84$ & $4.1-4.4 .62$ & $5.35-5.92$ & $7.02-8.06$ \\
Notch frequency [GHz] & 3.5 & 4.35 & 5.5 & 7.5 \\
Simulated notch frequency [GHz] & 3.51 & 4.36 & 5.55 & 7.54 \\
Calculated slot length mm & 26.33 & 21.18 & 16.75 & 12.29 \\
Optimized slot length mm & 25.9 & 20.8 & 19.23 & 11.5 \\
\hline
\end{tabular}

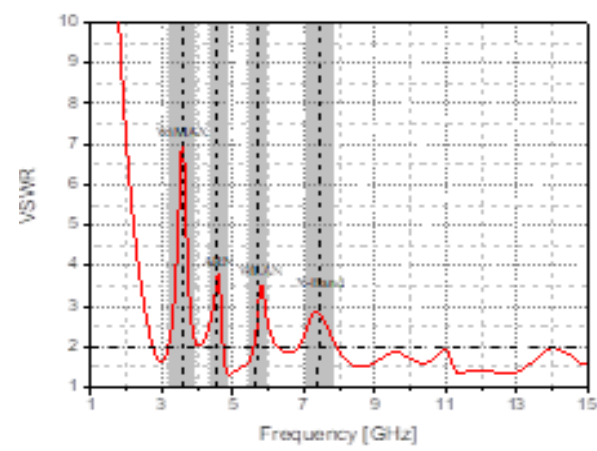

Figure 11. The simulated VSWR for the investigated antenna with quadruple notched filters

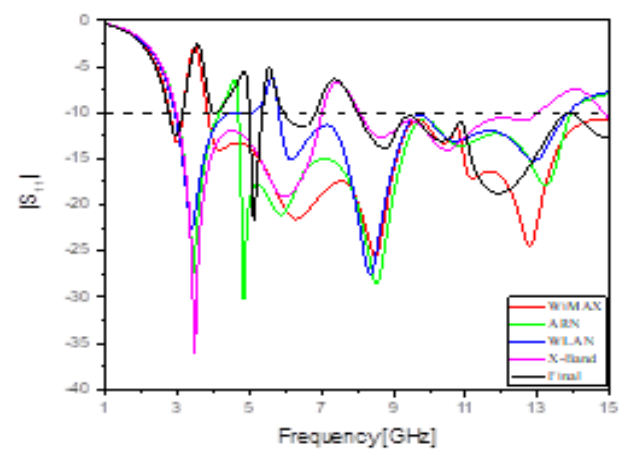

Figure 12. the effect of compound all four filters in one patch antenna

Figure 13 demonstrated the maximum gain of the final proposed antenna with gain from $2.2 \mathrm{~dB}$ to $4.8 \mathrm{~dB}$, while the gain of the notched filter for WiMAX, ARN, WLAN, and X-Band being -3,2.6,1, and 2.8 $\mathrm{dB}$ respectively. From Figure 13 seen that the gain became worse at higher frequencies from 10.1-11.5 GHz and seems as a reject filter with resonant frequency $10.8 \mathrm{GHz}$, this case is not investigated here as the investigated UWB in our case from 3.1 to $10.6 \mathrm{GHz}$. The radiation efficiency is shown in Figure 14 as shown it is low for the rejected bands.

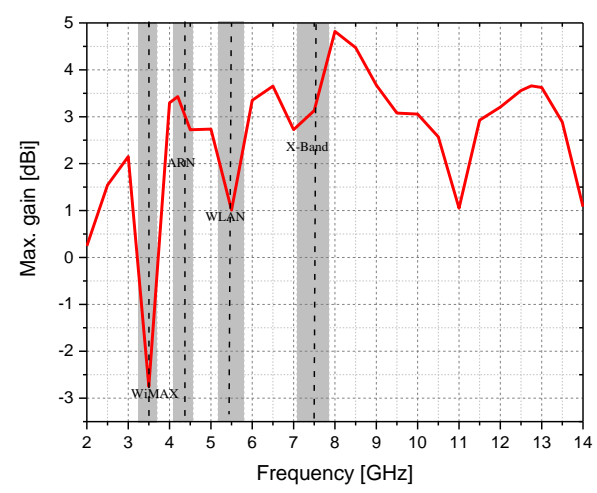

Figure 13. Max gain for the investigated antenna with quadruple notched filters

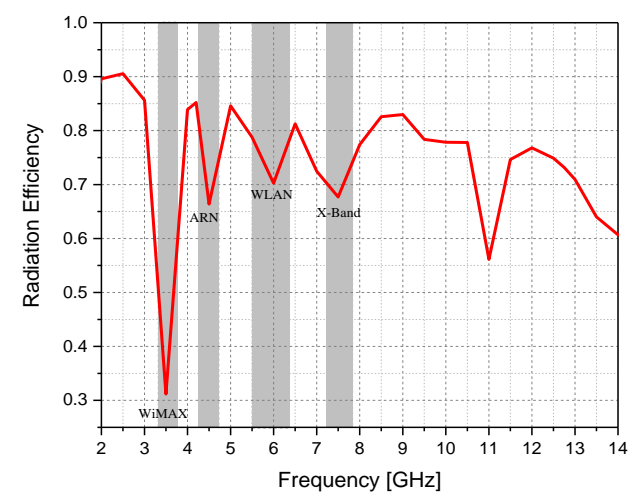

Figure 14. The radiation efficiency of the investigated antenna with quadruple notched filters

Finally, the radiation pattern of E-plane and H-plane of the proposed antenna with quadruple band notched filters is presented for 5 different resonant frequencies 3, 5.2, $6.5,8.8,10.3$, and $12 \mathrm{GHz}$, are demonstrated in Figure 15 (a)-(e) respectively. The radiation pattern is about omnidirectional at lower frequencies and became more directional at higher frequencies, while became worsens at higher frequency side due to of the existance of higher order modes. 


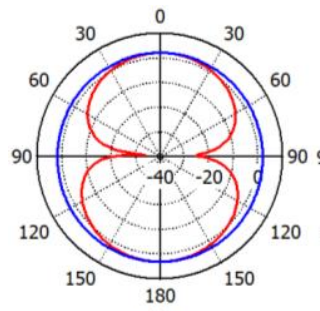

(a)

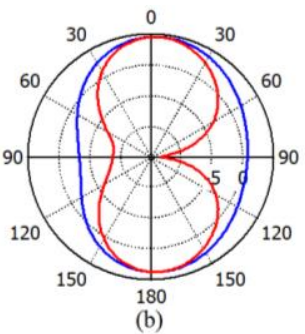

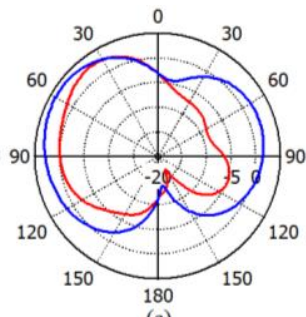

(c)

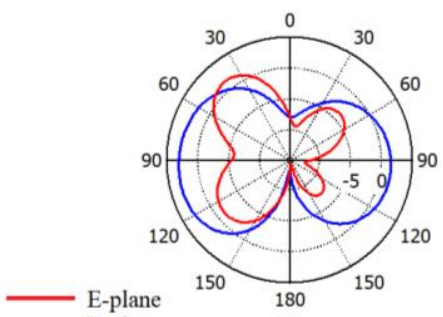

(d)

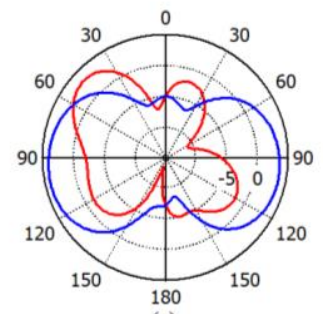

(e)

Figure 15. The simulated radiation pattern for different resonate frequencies for the proposed antenna

\section{A COMPARISON OF THE INVESTINATED ANTENNA WITH THE OTHER REPORTED WORK}

To see the effective of the proposed antenna a comparison with other reported works in terms of antenna dimension, operating band, number of notched filter peak gain, and the fractional bandwidth is listed in Table 4. From the table, it is evident that the dimensions of the antenna are acceptable compared with other works. The fractional bandwidth of the different reported works varies from $117.88 \%$ to $133.3 \%$, while this work is $129 \%$ in [22] the fractional bandwidth is more than in this work which equal $133.3 \%$ but when compared the bandwidth of the notched band this work is narrower the it.

Table 4. Comparison of the investigated antenna with other reported woks

\begin{tabular}{|c|c|c|c|c|c|c|}
\hline Ref. & $\begin{array}{l}\text { Ant. Dimension } \\
{\left[\mathrm{mm}^{3}\right]}\end{array}$ & $\begin{array}{c}\text { Operating } \\
\text { frequency }[\mathrm{GHz}]\end{array}$ & No. of band notch $[\mathrm{GHz}]$ & $\begin{array}{c}\text { BW of notched } \\
\text { bands [GHz] }\end{array}$ & $\begin{array}{l}\text { Peak gain } \\
{[(\mathrm{dBi}]}\end{array}$ & $\begin{array}{c}\text { Fractional } \\
\text { bandwidth \% }\end{array}$ \\
\hline \multirow[t]{4}{*}{ [18] } & $27 \times 36 \times 1.6$ & $2.95-12.65$ & WiMAX (3.26-3.9) & 0.64 & $<6.15$ & 124.36 \\
\hline & & & ARN (4.35-5.05) & 0.7 & & \\
\hline & & & WLAN (5.5-5.65) & 0.15 & & \\
\hline & & & ITU-8 (7.95-9.35) & 1.4 & & \\
\hline \multirow[t]{5}{*}{ [19] } & $30 \times 33.5 \times 0.8$ & $2.88-12.67$ & WiMAX (3.43-3.85) & 0.42 & N/A & 125.9 \\
\hline & & & WLAN (5.26-6.01) & 0.75 & & \\
\hline & & & $\mathrm{X}$-band satellite & 0.63 & & \\
\hline & & & communication (7.05-7.68) & & & \\
\hline & & & ITU 8 GHz (8.08-8.87) & 0.79 & & \\
\hline \multirow[t]{4}{*}{ [20] } & $30 \times 28 \times 0.508$ & $3-11$ & WiMAX (3.3-3.36) & 0.06 & $<5$ & 128.6 \\
\hline & & & IVSAT $(4.50-4.70)$ & 0.2 & & \\
\hline & & & Lower WLAN (5.15-5.35) & 0.2 & & \\
\hline & & & Upper WLAN (5.70-5.825) & 0.125 & & \\
\hline \multirow[t]{4}{*}{ [22] } & $43 \times 28 \times 1.6$ & $2.8-14$ & WiMAX (2.7-3.4) & 0.7 & $<6.4$ & 133.3 \\
\hline & & & C-band (3.4-4.5) & 1.1 & & \\
\hline & & & WLAN (5.4-6.1) & 0.7 & & \\
\hline & & & X-band (6.8-9.9) & 3.1 & & \\
\hline \multirow[t]{4}{*}{ [23] } & $26 \times 28 \times 0.4$ & $3.1-12$ & WLAN (5.1-5.43) & 0.33 & $>6$ & 117.88 \\
\hline & & & WLAN(5.78-5.98) & 0.17 & & \\
\hline & & & X-Band (7.2-7.79) & 0.59 & & \\
\hline & & & ITU (8.03-8.83) & 0.8 & & \\
\hline \multirow[t]{4}{*}[25]{} & $28 \times 30 \times 1.524$ & $2.6-12$ & S-band (2.70-3.10) & 0.4 & 4.75 & 128.76 \\
\hline & & & downlink C-band (3.70-4.20) & 0.5 & & \\
\hline & & & WLAN (4.90-5.75) & 0.85 & & \\
\hline & & & WPAN (6.60-7.40) & 0.8 & & \\
\hline \multirow{4}{*}{$\begin{array}{l}\text { This } \\
\text { work }\end{array}$} & $36 \times 24 \times 1.6$ & $3.02-14$ & WIMAX (3.18-3.84) & 0.66 & 4.8 & 129 \\
\hline & & & $\mathrm{ARN}(4.1-4.4 .62)$ & 0.52 & & \\
\hline & & & WLAN (5.35-5.92) & 0.57 & & \\
\hline & & & X-Band (7.02-8.06) & 1.02 & & \\
\hline
\end{tabular}




\section{CONCLUSION}

In this paper, quadruple notched frequency bands ultra-wideband (UWB) monopole antenna has been introduced. The antenna has a semicircular-shaped patch and printed on FR4 subtract of a compact size $36 \times 24 \mathrm{~mm}$. The antenna has a fractional bandwidth of $129 \%$. Four different slots configurations with optimized dimensions have been inserted in the antenna elements for achieving quadruple notched narrow bands as; mirrored L-shaped connected from the top slot was etched on the feed line for eliminating WiMAX spectrum, inverted U-shaped was etched on the patch for suppressing ARN frequency range, a split ring resonator (SRR) was inserted on the patch for stopping WLAN confliction, and L-shaped slot was etched on the partial ground plane for X-band suppression. The simulation study shows that the antenna has a good impedance bandwidth, a maximum gain more than $4.5 \mathrm{dBi}$, a radiation efficiency more than $80 \%$ over the UWB spectrum, and radiation pattern for different resonant frequencies were demonstrated. The antenna performance has been verified through the comparison study with other design reported in the literature.

\section{REFERENCES}

[1] Federal Communications Commission, "Revision of Part 15 of the commission's rules regarding ultra-wideband transmission systems," First Report and Order, FCC 02, V48, Apr 2002.

[2] Majed O. Dwairi, Mohamed S. Soliman, Ahmad A. Alahmadi, Sami H. A. Almalki, Iman I. M. Abu Sulayman, "Design and Performance Analysis of Fractal Regular Slotted-Patch Antennas for Ultra-Wideband Communication Systems," Wireless Personal Communications, vol. 105(3), pp. 819-833, Apr 2019.

[3] Majed O Dwairi, Mohamed S Soliman, Ahmad A Alahmadi, Iman IM Abu Sulayman, Sami H. A. Almalki, "Design regular fractal slot-antennas for ultra-wideband applications," Progress In Electromagnetics Research Symposium-Spring (PIERS), pp. 3875-3880, 2017.

[4] Mohamed S. Soliman, Majed O. Dwairi, Iman I. M. Abu Sulayman, "The Effect of the Ground Slots up on the Bandwidth Performance for UWB Antenna," International Journal of Engineering Research and Technology, vol. 12, pp. 227-230, 2019.

[5] Mohamed S. Soliman, Majed O. Dwairi, Ahmad A. Alahmadi, "Design and Performance Analysis of an UWB Patch Antenna with Enhanced Bandwidth Characteristics," Proceedings of 12th European Conference on Antennas and Propagation (EuCAP 2018), Apr 2018.

[6] Mohamed S. Soliman, Majed O. Al-Dwairi, Amjad Y. Hendi, and Ziad Alqadi, "A Compact Ultra-Wideband Patch Antenna with Dual Band-Notch Performance for WiMAX / WLAN Services," IEEE Jordan International Joint Conference on Electrical Engineering and Information Technology, pp. 72-76, Apr 2019.

[7] Amir, Alimgeer Khurram Saleem, Iftikhar Adnan, Ijaz Bilal, Kim Kang Wook, Mohyuddin, "Dual notch band UWB antenna with improved notch characteristics," Microwave and Optical Technology Letters, vol 60(4), pp. 925-930, 2017.

[8] Zahra Esmati, Mahdi Moosazadeh, "Design of Compact Dual Band-Notched UWB Antenna using Slotted Conductor-Backed Plane," Arabian Journal for Science and Engineering, vol. 39(6), pp. 47-4713. 2014.

[9] Hui Li, Le Kang, Da-Wei Mi, and Ying-Zeng Yin, "Simple Dual Band-Notched Uwb Antenna Loaded With Single U-Shaped Resonator," Microwave and Optical Technology Letters, vol. 57(9), pp. 2129-2134, 2015.

[10] J. Kazim, A. Bibi, M. Rauf, M. Tariq, Owais, "A compact planar dual band-notched monopole antenna for UWB application,” Microw. Opt. Technol. Lett., vol. 56(5), pp. 1095-1097, 2014.

[11] Si-Yan Chen and Qing-Xin Chu, "A Reconfigurable Dual Notched-Band UWB Antenna," 2015 IEEE 4th AsiaPacific Conference on Antennas and Propagation (APCAP), pp. 103-104, 2015.

[12] Swati Yadav, Anil Kumar Gautam and Binod Kumar Kanaujia, "Design of dual band-notched lamp-shaped antenna with UWB characteristics," International Journal of Microwave and Wireless Technologies, vol. 9(2), pp. 395-402, 2017.

[13] Mahmoud Bahmani, Jalil Mazloum, Naser Ojaroudi P, "Compact Dual Band-Notched Monopole Antenna with Modified Radiating Patch for UWB Wireless Applications," Wireless Pers Commun, vol. 96, pp. 125-134, 2017.

[14] Jeet Banerjee et al., "A Compact Printed UWB Monopole Antenna with Triple Band Notch Characteristics," 2018 3rd International Conference on Microwave and Photonics (ICMAP 2018), F eb 2018.

[15] Debdeep Sarkar et al., "Compact Microstrip-Fed Triple Band-Notched UWB Monopole Antenna," IEEE Antennas and Wireless Propagation Letters, vol. 13, pp. 396-399, 2014.

[16] Wasan H. Althubitat Al Amro, Mohamed K. Abdelazeez, "Monopole Tri-Band Notched Characteristics UWB Antenna for WiMAX, C-Band, WLAN and X-Band Applications," 2018 9th International Conference on Information and Communication Systems (ICICS), pp. 198-202, 2018.

[17] Manish Sharma et al., "Compact printed high rejection triple band-notch UWB antenna with multiple wireless applications," Engineering Science and Technology, an International Journal, vol. 19, pp. 1626-1634, 2016.

[18] Hari Shankar Mewara et al., "A printed monopole ellipzoidal UWB antenna with four band rejection Characteristics," International Journal of Electronics and Communications, pp. 222-231, 2018.

[19] Yunnan Jin, Jinpil Tak, Jaehoon Choi," Quadruple Band-Notched Trapezoid UWB Antenna with Reduced Gains in Notch Bands," Journal Of Electromagnetic Engineering And Science, nol. 16(1), pp. 35 43, Jan. 2016.

[20] Muhibur Rahman, Dong-Sik Ko, and Jung-Dong Park, "A Compact Multiple Notched Ultra-Wide Band Antenna with an Analysis of the CSRR-TO-CSRR Coupling for Portable UWB Applications," Sensors, vol. 17(10), pp. 2174, 2017. 
[21] Y. Zehforoosh et al., "Designing Four Notched Bands Microstrip Antenna for UWB Applications, Assessed by Analytic Hierarchy Process Method," Journal of Microwaves, Optoelectronics and Electromagnetic Applications, vol. 16(3), Sep 2017.

[22] Raed Abdulkareem Abdulhasan, Rozlan Alias, and Khairun Nidzam Ramli, "A Compact CPW Fed UWB Antenna with Quad Band Notch Characteristics for ISM Band Applications," Progress in Electromagnetics Research M, vol. 62, pp. 79-88, 2017.

[23] Xiaoyin Li, Lianshan Yan, Wei Pan, and Bin Luo, "A Compact Printed Quadruple Band-Notched UWB Antenna," International Journal of Antennas and Propagation, vol. 2013.

[24] Reshma Babu G, Chithra Thampi, Shameer K Mohammed, "Cpw Feed Uwb Antenna with Quad Band Notches," International Research Journal of Engineering and Technology, vol. 05(3), Mar 2018.

[25] Asim Quddus et al., "Ultra Wideband Antenna with Quad Band Rejection Characteristics," Proceedings of ISAP2016, Okinawa, Japan, 1090-1091

[26] Hari Shankar Mewara, Jitendra Kumar Deegwal, Mahendra Mohan Sharma, "A slot resonators based quintuple band-notched Y-shaped planar monopole ultra-wideband antenna," Int. J. Electron. Commun. (AEÜ), vol. 83, pp. 470-478, 2018.

[27] Muhibur Rahman, Wasif Tanveer Khan, Muhammad Imran, "Penta-notched UWB antenna with sharp frequency edge selectivity using combination of SRR, CSRR, and DGS," Int. J. Electron. Commun. (AEÜ), vol. 93, pp. 116-122, 2018.

[28] Muhibur Rahman, and Jung-Dong Park, "The Smallest Form Factor UWB Antenna with Quintuple Rejection Bands for IoT Applications Utilizing RSRR and RCSRR,” Sensors, vol. 18, pp. 911, 2018.

\section{BIOGRAPHY OF AUTHOR}

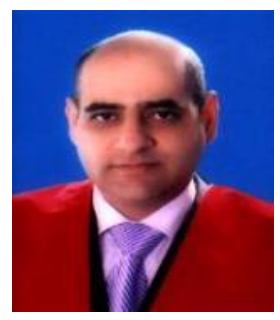

Majed O. Dwairi: An associate professor in the department of communication Engineering, Faculty of Engineering Technology/Al-Balqa Applied University Amman-Jordan. His research interests include optical communication, wireless communications, signal and image processing, UWB microstrip patch antennas, dielectric Resonant antennas, optimization techniques in antenna design and antenna measurement techniques.Dr. Dwairi is a member of the IEEE-AP Society. 